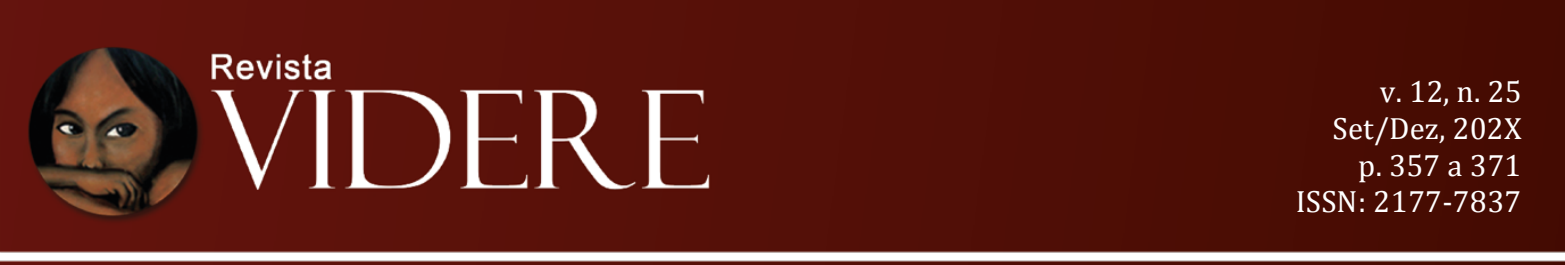

\title{
O EXERCÍCIO DA CIDADANIA REPRODUTIVA OBSTADO PELA IRREFLEXÃO E PELA BALANIDADE DO MAL, DO PENSAMENTO DE HANNAH ARENDT
}

\author{
THE EXERCISE OF REPRODUCTIVE CITIZENSHIP PREVENTED BY THE \\ IRREFLECTION AND THE BALANITY OF EVIL, FROM THE THOUGHT OF \\ HANNAH ARENDT
}

\author{
EL EJERCICIO DE CIUDADANÍA REPRODUCTIVA IMPEDIDA POR LA \\ IRREFLEXIÓN Y LA BANALIDAD DEL MAL, DEL PENSAMIENTO DE HANNAH \\ ARENDT
}

Ana Carolina Pedrosa Massaro Mestra em Direitos Coletivos e Cidadania Universidade de Ribeirão Preto anacarolina@mjmadvogados.com.br OrcidID: https://orcid.org/0000-0002-2548-1870

\begin{abstract}
Maria Cristina Vidotte Blanco Tárrega
Doutora em Direito Empresarial Universidade de Ribeirão Preto Professora do Curso de Direito, do Mestrado e do Doutorado da UFG mcvidotte@gmail.com OrcidID: https://orcid.org/0000-0002-4805-4345
\end{abstract}

Resumo: O presente artigo tem por escopo analisar o exercício da cidadania reprodutiva a partir da conceituação de Hannah Arendt sobre a irreflexão e a consequente banalidade do mal. Com efeito, pretende-se, por meio deste estudo, fazer um comparativo entre as observações Arendtianas sobre a forma irracional de simplesmente obedecer ordens e seguir um código de ética pré-determinado, sem refletir sobre a conduta tomada, levando-se à banalidade do mal descrita pela filósofa quando do julgamento de Eichmann, com as práticas médicas que viabilizam, a qualquer custo, a reprodução artificial, a ceivar cidadania reprodutiva dos envolvidos no ato.

Palavras-chave: Banalidade do mal. Irreflexão. cidadania reprodutiva. direitos humanos. 
Abstract: The aim of this article is to analyze the exercise of reproductive citizenship based on Hannah Arendt's concept of thoughtlessness and the consequent banality of evil. In fact, it is intended, through this study, to make a comparison between Arendtian observations on the irrational way of simply obeying orders and following a predetermined code of ethics, without reflecting on the conduct taken, leading to the banality of poorly described by the philosopher at the time of Eichmann's judgment, with the medical practices that make artificial reproduction, at any cost, mowing the reproductive citizenship from those who are involved in the act.

Keywords: Banality of evil. thoughtlessness. reproductive citizenship. human rights.

Resumen: El propósito de este artículo es analizar el ejercicio de la ciudadanía reproductiva a partir del concepto de irreflexión y consecuente banalidad del mal de Hannah Arendt. En efecto, a través de este estudio se pretende hacer una comparación entre las observaciones de Arendt sobre la forma irracional de simplemente obedecer órdenes y seguir un código ético predeterminado, sin reflexionar sobre la conducta adoptada, lo que lleva a la banalidad de mal descrito por la filósofa en la época del juicio de Eichmann, con las prácticas médicas que hacen factible la reproducción artificial, a cualquier precio, para reclamar la ciudadanía reproductiva a los implicados en el acto.

Palabras clave: Banalidad del mal. Irreflexión. ciudadanía reproductiva. derechos humanos.

\section{Introdução}

Em meio aos horrores produzidos pelo Nazismo, uma filósofa do gênero feminino, alemã e judia se dedicou a estudar as motivações que levaram o pensamento humano a produzir tanta dor, sofrimento e separação. Inserido neste contexto de indignação e busca por explicações, este artigo pretende expor os pensamentos da filósofa Hannah Arendt acerca do termo banalidade do mal, fazendo-se, posteriormente, uma comparação entre a ausência da atividade de pensar e julgar, observadas por ela durante o julgamento de Eichmann - carrasco nazista e um dos grandes responsáveis pelo extermínio de judeus na Alemanha -, com a maneira pela qual são intentadas as práticas médicas que conduzem à reprodução humana medicamente assistida, especialmente a gestação por substituição, a ceivar a cidadania reprodutiva dos envolvidos.

Assim, a partir da reflexão sobre os perigos existentes em não pensar, não refletir, obedecer cegamente um código de ética pré-existente, estabelece-se neste artigo um paralelo com a atividade médica de buscar a procriação a qualquer custo, analisando não somente a conduta dos profissionais da área, mas notadamente de que forma a ausência de pensamento, de reflexão sobre a eticidade do ato e, sobretudo, sobre as consequências sociais e jurídicas do 
efetivo desrespeito dos direitos humanos, sexuais e reprodutivos dos envolvidos, a promover uma banalização do mal e, com isso, a negatória da cidadania reprodutiva.

\section{A banalidade do mal proposta por Hannah Arendt}

Hannah Arendt nasceu em Hannover, na Alemanha, em 1906. De origem judaica, refugiou-se nos Estados Unidos da América durante o Nazismo e acompanhou, como jornalista correspondente do jornal The New Yorker, o julgamento de um dos maiores exterminadores de judeus do século XX, o comandante do Reich, Adolf Eichmann. Em tal evento, ela teve a oportunidade de entrevistar pessoalmente o acusado e, para seu espanto, concluiu tratar-se de um ser humano irreflexível. Apesar da crueldade inimaginável de suas atitudes e de todas as atrocidades que cometeu, Eichmann mostrou-se, nos dizeres de Hannah Arendt, "ordinário, comum, nem demoníaco, nem monstruoso." (BIGNOTTO; MORAES, 2003)

A partir desta constatação, Hannah escreveu a obra "Eichmann em Jerusalém: um relato sobre a banalidade do mal" (ARENDT, 1999), na qual se deteve a analisar o mal que advém da ausência de reflexão sobre atos e condutas, o obedecer cegamente a um código de ética pré-determinado, sem questionar, sem pensar sobre o que está de fato fazendo.

Esta linha de raciocínio foi duramente criticada no século $\mathrm{XX}$, pois acreditouse que Hannah Arendt havia sido benevolente com o maior exterminador de judeus que a História conheceu, eximindo-lhe da culpa pelas barbáries cometidas, sob o pretexto de que ele de fato não saberia o que estava fazendo, pois nunca havia pensado a respeito, era um mero cumpridor de ordens.

Ocorre que as implicações morais e sociais da irreflexão apontada por Arendt não se limitavam apenas a condenar ou absolver culpados pelo holocausto, mas, sobretudo, foi uma maneira corajosa e objetiva de entender o que realmente havia nas mentes daquelas pessoas que participaram ativamente do aniquilamento do povo judeu alemão.

Com efeito, em momento algum a filósofa isentou Eichmann de sua culpa. Pelo contrário, entendeu que todos os participantes do Reich eram culpados por seus atos, mas era necessário observar certa distinção entre os graus de responsabilidades dos líderes do movimento totalitário e da grande massa burocrática que cumpria friamente as ordens da cúpula nazista. 
Baseada ainda nesta conclusão, Hannah divergiu também da então conhecida teoria da engrenagem (cog-theory) ${ }^{1}$, a partir da qual todos os integrantes de um sistema eram tidos como simples peças de uma grande engrenagem e, portanto, não agiam por seus próprios pensamentos, o que significaria isentá-los de culpa e responsabilidades individuais.

A filósofa jamais concordou que o não pensar implicasse em isenção de culpa, mas observou que havia um enorme abismo entre as atrocidades cometidas por Eichmann e a superficialidade reflexiva do agente responsável pelos ditos atos, o que chamou de banalidade do mal.

Hannah Arendt questionava as consequências advindas do não pensar, do não refletir, do ser guiado pelo que outros pensaram, e o fazia com o intuito não de escusar os não pensantes, mas de demonstrar que situações gravíssimas e dramáticas podem ser geradas diante da irreflexão.

Mais do que isso, Arendt analisa profundamente em suas obras o vínculo entre pensar e agir, questionando se a simples atividade de pensar seria suficiente para evitar que uma pessoa faça o mal, ou que seja ainda determinante para que ela faça necessariamente o bem. Nestes termos, dizia ela:

\footnotetext{
1 "As críticas de Hannah Arendt ao comportamento moral de judeus e alemães tiveram como objetivo desconstruir algumas argumentações vigentes à época, que tentavam explicar o fracasso moral vivenciado na Europa daqueles tempos sombrios. Dentre tais argumentações, destacarei três: 1) a teoria da peça de engrenagem; 2) a teoria da culpa coletiva; e 3) a teoria da voz da consciência. A teoria da peça de engrenagem foi utilizada tanto pela defesa de Eichmann quanto pela acusação. Segundo a defesa, Eichmann era apenas uma pequena engrenagem na maquinaria chamada solução final para a questão judaica. A promotoria, seguindo a mesma lógica, via naquele homem não uma engrenagem, mas o motor do Holocausto. Para Arendt, aquele homem tolo, sem iniciativas, de mediocridade e superficialidade aparentes, um oficial subalterno, que sempre agia ancorado por leis e memorandos, não era motor de coisa alguma. No entanto, ela estava de acordo que, para as ciências políticas, era importante entender que a essência do governo totalitário, e talvez a natureza burocrática, seja transformar homens em funcionários e meras engrenagens, assim os desumanizando (Arendt, 1999, p. 312). Hannah Arendt também estava convencida do fato de Eichmann pertencer a uma estrutura organizacional e de que poderia ser trocado, como uma peça, por outro burocrata qualquer, que faria a mesmíssima coisa em seu lugar, pois afinal não se tratava de uma maldade específica (demoníaca, patológica ou ideológica), mas do cumprimento de funções de Estado. Tal realidade não desresponsabilizava, em hipótese alguma, essa pequena engrenagem dos atos monstruosos que foram cometidos. Na medida em que a pequena engrenagem comete crimes, num tribunal sua ação deve ser julgada como uma ação supostamente criminosa até que se prove o contrário, pois Eichmann, como qualquer outro burocrata, tinha, sim, responsabilidades, pois tinha a possibilidade de escolha, inerente à sua condição humana. Ainda que levasse em conta tal teoria, a tentativa da defesa era estupidamente equivocada, pois seria difícil, senão impossível, encontrar atenuantes para os seus crimes. A fidelidade ao trabalho realizado, tantas vezes declarada pelo réu, era um agravante. Se ele se tivesse apresentado à corte dizendo que era obrigado a fazer o que fazia, mas procurava não cumprir plenamente as ordens recebidas a fim de salvar vidas, ele ainda assim seria responsável, mas talvez pudesse contar com alguns atenuantes. Porém Eichmann dizia-se um cumpridor fiel das ordens, que seu ideal de vida era cumprir seu dever e fazer seu trabalho com precisão e eficiência e, ainda mais, sentia-se envergonhado quando no tribunal era levado a admitir que não cumpria algumas ordens recebidas, ainda que essa desobediência tivesse significado salvar centenas de vidas humanas. A teoria da engrenagem, ainda que possa ser útil à ciência política, passa à margem da questão da responsabilidade pessoal (Correia, 2004, p. 94). E esse era um tema ético central para Hannah Arendt (2004, p. 87), pois a responsabilidade pessoal não pode ser transferida para um sistema, ainda que se trabalhe sob uma ditadura. Ao rebater essa teoria, a autora insiste na liberdade que caracteriza fundamentalmente a ação humana, que funda e exige toda e qualquer formação moral." (ANDRADE, 2010)
} 
Será que a natureza da atividade de pensar, o hábito de examinar, refletir sobre qualquer acontecimento, poderia condicionar as pessoas a não fazer o mal? Estará entre os atributos da atividade do pensar, em sua natureza intrínseca, a possibilidade de evitar que se faça o mal? Ou será que podemos detectar uma das expressões do mal, qual seja, o mal banal como fruto do não exercício do pensar? (ARENDT, 2009)

Pensar sobre as consequências do não pensar foi objeto de estudo da mencionada filósofa do século XX e, certamente, não apenas sua visão como cientista política, mas, sobretudo, como parte integrante da comunidade judaica, perseguida e massacrada durante o Nazismo, foi decisiva para analisar e compreender como as atitudes advindas da irracionalidade, da irreflexão, são tão, ou mais, devastadoras que aquelas oriundas da meditação e do planejamento, uma vez que a simples associação do fenômeno do mal com a ética tinha se tornado insuficiente para explicar todo o horror e as barbáries cometidas na Alemanha durante o Nazismo.

Era o verdadeiro colapso moral e a situação exigia que se aprofundasse o raciocínio a fim de se chegar à verdadeira ligação que há entre pensar e agir. Era preciso saber se a atividade humana do pensamento está ou não ligada à conduta ética de discernir entre o certo e o errado.

Importante observação foi feita por Hannah Arendt quando trouxe à baila a expressão banalidade do mal:

Por traz da expressão (banalidade do mal) não procurei sustentar nenhuma tese ou doutrina, muito embora eu estivesse consciente de que ela se opunha à nossa tradição de pensamento literário, teológico ou filosófico, sobre o fenômeno do mal (SOUKI, 1998)

Assim, o que se observa é que Arendt relacionou toda a maldade e as atrocidades cometidas pelos carrascos nazistas, que simplesmente obedeciam às ordens emanadas de Hitler, à ausência de reflexão ou pensamento sobre a lei vigente à época. É natural do ser humano mentalmente sadio distinguir o certo do errado, desde que reflita sobre isso, e não é preciso ser inteligente para fazê-lo. Para Hannah Arendt todo ser humano é capaz de pensar e esta teoria contrariava a posição de Kant, que acreditava que tal atributo era exclusivo dos filósofos.

Neste contexto, cumprir cegamente ordens deixa o homem refém daqueles que as estipulam e, por óbvio, retira-lhe a criticidade e, até mesmo, a autocrítica. Por tal motivo, os carrascos nazistas não tiveram conflito algum de consciência, porque jamais chegaram a questionar a realidade fática em que estavam inseridos, e foi nestes termos que Hannah 
Arendt, ao escrever sua obra $A$ Vida do Espírito, discorreu sobre as duas vertentes do pensamento: os perigos existentes tanto na atividade de pensar como na ausência de pensamento, que pode levar à maldade.

A autora afirma que

Há alguns anos, em relato sobre o julgamento de Eichmann em Jerusalém, mencionei a "banalidade do mal". Não quis, com a expressão, referir-me a teoria ou doutrina de qualquer espécie, mas antes a algo bastante factual, o fenômeno dos atos maus, cometidos em proporções gigantescas - atos cuja raiz não iremos encontrar em uma especial maldade, patologia ou convicção ideológica do agente; sua personalidade destacava-se unicamente por uma extraordinária superficialidade. (ARENDT, 2009)

Neste diapasão, Arendt sustentou que o mal não poderia ser explicado como uma fatalidade, mas sim caracterizado como uma possibilidade da liberdade humana. Foi assim que ela afirmou por diversas vezes que Eichmann foi um bom pai de família, um filho exemplar e um irmão dedicado, mas também foi um grande assassino, capaz das maiores crueldades e atrocidades.

O mal encontrado em Eichmann foi definido como banal por não ter explicação, motivação, ideológica, patológica ou qualquer questão demoníaca. O conceito de Hannah Arendt de mal banal se refere a um fenômeno sem inspiração própria, mas nem por isso deixa de ser assombroso em suas consequências. Havia um abismo entre a gravidade dos atos e a superficialidade das motivações que levaram Eichmann a ser o maior carrasco Nazista da História. Nestes termos, Arendt conseguiu apontar o ineditismo do mal efetivado pelos burocratas nazistas, que executavam ordens sem se questionar sobre o que estavam fazendo.

No pensamento elaborado por Hannah Arendt, seguir friamente um código de ética pré-determinado, fazendo-o de forma irreflexível, é capaz de produzir uma maldade sem precedentes, pelo que é preciso estimular o pensamento crítico do ser humano independentemente do seu grau de intelectualidade e do cargo que ele ocupe -, a fim de evitar que barbáries como as que foram cometidas durante o Nazismo voltem a ocorrer.

\section{Sobre Adolf Eichmann e a irracionalidade}

Eichmann nasceu no mesmo ano que Hannah Arendt, 1906, no dia 19 de março, na cidade de Solingen, no norte da Alemanha e morreu enforcado em Jerusalém, na prisão de Ramleh, em 31 de maio de 1962, por ter sido condenado pelos crimes de guerra cometidos 
durante o Nazismo. Dentre as acusações que lhe pesavam estavam crimes contra a humanidade, crimes contra o povo judeu e de pertencer a uma organização criminosa.

No fim da Segunda Guerra Mundial, em maio de 1945, ele foi capturado por tropas americanas, mas escapou do campo de prisioneiros em que estava confinado e fugiu para a Argentina, onde constituiu uma nova identidade, passando a usar o nome de Ricardo Klement. Contudo, seus esforços foram em vão, pois, após 15 (quinze) anos de fuga, em 1960 foi capturado pelo serviço secreto israelense e levado a julgamento em Jerusalém.

Eichmann foi, no terceiro Reich, o comandante responsável por "solucionar as questões judaicas", organizando a expulsão dos judeus e, por fim, encaminhando-os para as câmaras de extermínio. Desde que ele assumiu o cargo, 45.000 (quarenta e cinco mil) judeus deixaram a Áustria e 19.000 (dezenove mil) deixaram a Alemanha, isso em apenas 8 (oito) meses. Passado um ano e meio, mais de 148.000 (cento e quarenta e oito mil) judeus haviam sido expulsos, ou seja, 60\% (sessenta por cento) da população judia dos países dominados pelo nazismo (ARENDT, 1999).

O comandante em voga tinha muita destreza em realizar duas importantes tarefas: negociar e organizar, pelo que teve êxito em retirar tantos judeus da Alemanha e dos países dominados pelo Nazismo, fazendo-o em tão curto espaço de tempo, e, por mais horrendo que isso possa parecer, o fez de forma "legal", ou seja, cumpriu com subserviência exemplar os comandos que lhe foram dirigidos e respeitou cada linha do código de ética adotado pelo Partido Nacional Socialista.

Todas as atitudes de Eichmann visavam a um único propósito: obter uma patente. Diz Arendt:

Com sua sincera devoção, questões de família e de carreira pessoal, era o último e já degenerado produto da crença do burguês na suma importância do interesse privado. [...] É o burguês isolado da sua própria classe, o indivíduo atomizado produzido pelo colapso da própria classe burguesa. (ARENDT, 1998)

A crueldade e a frieza dos atos de Eichmann podem sugerir tratar-se de um ser monstruoso, demoníaco e que calculava cuidadosamente todos os seus passos. Mais do que isso, podia-se pensar que o tal comandante fosse consciente de si e muito bem sucedido em seus intentos.

Ocorre que a verdade é diametralmente distante disso, Eichmann era, de fato, um ser irreflexível, ele não pensava por si próprio, era um mero cumpridor de leis e ordens, e buscava enquadrar-se no sistema simplesmente para ser reconhecido e congratulado. 
Originário de uma família de classe média, Eichmann era dotado de mediana inteligência e detentor de um discurso robotizado, sempre embasado em frases feitas, clichês e repetições de pronunciamentos alheios. Não havia nele convicção para se filiar ao partido Nacional Socialista, mas o fez sem jamais permitir se convencer por aquela ideologia.

Nunca foi dado aos estudos e desde criança se saia muito mal na escola, chegando até mesmo a abandonar o curso de engenharia no qual se matriculou. Prestava serviços ordinários na modesta empresa de mineração do seu pai e de lá saiu para empregar-se na Elekstrobau, onde permaneceu apenas por dois anos até ser demitido.

Ironicamente, por indicação de um primo judeu de sua madrasta, Eichmann conseguiu enfim uma boa colocação em uma Cia de Óleo a vácuo, lá permanecendo por 5 (cinco) anos até ser transferido e em seguida novamente demitido.

Tratava-se, pois, de um homem fracassado, mas com ambição suficiente para lhe direcionar na busca por uma colocação profissional que lhe permitisse construir uma carreira. Tal intento foi viabilizado pelo convite do sócio de seu pai, o senhor Kaltenbrunner, em 1932, para que o então rapaz se filiasse ao Partido Nacionalista e se tornasse soldado do exército alemão.

Assim, ao filiar-se ao Nazismo, Eichmann não pretendia outra coisa senão galgar um cargo melhor do que aquele que ocupava como vendedor da Cia de óleo em comento, pois acreditava que a figura de um militar lhe traria concretas oportunidades de exercer feitos admiráveis e, quem sabe, ser congratulado com uma patente, mesmo que isso dependesse de torturar, agredir ou matar seres humanos. A crueldade de seus atos era vista por ele próprio como um mero cumprimento de ordens, não lhe gerando qualquer tipo de arrependimento ou auto reprovação.

Neste contexto, o que se observou foi que as maldades cometidas por Eichmann não eram meditadas, tampouco se tratava de um ser estúpido, que não compreendia o que estava fazendo, mas de alguém que simplesmente não tinha a capacidade de refletir sobre seus atos, não pensava.

"Quanto mais se ouvia Eichmann, mais óbvio ficava que sua incapacidade de falar estava relacionada com sua incapacidade de pensar, ou seja, de pensar do ponto de vista de outra pessoa" (ARENDT, 1999).

Eichmann sequer chegou a ler Mein Kampf, de Adolf Hitler, e nunca demonstrou seguir a ideologia que embasou o Nazismo. Não odiava ou repudiava os judeus, mas foi um dos maiores responsáveis pelo Holocausto, sem apresentar jamais nenhum sinal de motivação para tanto. Quem chegou a conhecê-lo - e aqui se inclui sua auto avaliação -, nunca o viu de 
outra forma senão como um cidadão correto; que seguiu as normas de conduta espelhadas no código de ética da época em que viveu; cumpridor de suas obrigações e sem nenhum exagero ou fanatismo em seu comportamento cotidiano.

Arendt afirmou que "o problema com Eichmann era exatamente que muitos eram como ele, e muitos não eram pervertidos e nem sádicos, mas eram e ainda são terrível e assustadoramente normais" (ARENDT, 1999). E ela continua, "este era um novo tipo de criminoso, efetivamente hostis generis humani, que comete seus crimes em circunstâncias que tornam praticamente impossível para ele saber ou sentir que está agindo de modo errado." (ARENDT, 1999)

Até em suas últimas palavras antes de ser enforcado, Eichmann se utilizou de clichês e frases feitas para se referir ao seu próprio funeral, demonstrando inclusive certo entusiasmo com a situação: "Dentro de pouco tempo, senhores, iremos encontrar-nos de novo. Esse é o destino de todos os homens. Viva a Alemanha, viva a Argentina, viva a Áustria. Não as esquecerei." (ARENDT, 1999)

Arendt se vale deste momento para sintetizar toda sua lição sobre a banalidade do mal, pois este foi senão o ápice da irreflexão de Eichmann. Diz ela:

Diante da morte encontrou o clichê usado na oratória fúnebre. No cadafalso, sua memória lhe aplicou um último golpe: ele estava 'animado', esqueceu-se de que aquele era seu próprio funeral. Foi como se naqueles últimos minutos estivesse resumindo a lição que este longo curso de maldade humana nos ensinou - a lição da temível banalidade do mal, que desafia as palavras e os pensamentos. (ARENDT, 1999)

\section{$4 \mathrm{O}$ exercício da cidadania reprodutiva obstado pela irreflexão e pela balanidade do mal}

Após analisar e demonstrar toda a maléfica consequência advinda da irreflexão e da ausência de pensamento, faz-se salutar observar que tais condutas podem ser cotidianamente verificadas. No mundo contemporâneo o homem tutelado, guiado, subjugado é aquele submisso e vítima dos sistemas, que determinam o que o indivíduo deve consumir, o que deve fazer, como deve se portar, etc. São estes sistemas que ditam o "certo" e o "errado". Por outro lado, o homem esclarecido é aquele que tem o poder de decidir por si mesmo, sabe o que ele quer e consegue distinguir o que para ele é certo e errado.

Neste contexto, para o alcance da cidadania, é necessário que homens e mulheres estejam suficientemente instruídos sobre seus direitos, além de terem autonomia para exercê- 
los com segurança e privacidade. Assim, os direitos sexuais e reprodutivos são tidos como mais uma das esferas de direitos que instrumentalizam o alcance da cidadania.

A estudiosa brasileira Maria Betânia Ávila traz interessante definição para o termo "cidadania reprodutiva". Vejamos:

A cidadania tem sido trabalhada como instrumento de combate à desigualdade social, à conquista de direitos e como um meio de instituir um novo processo democrático assentado sobre o compromisso com a justiça social, com a ética e com uma moral que seja instauradora da dignidade humana, como valor coletivo que promova a superação dos preconceitos e discriminações. (AVILA, 2003)

Neste compasso, a sexualidade e a reprodução humana fazem parte da cidadania, ao passo que a possibilidade irrestrita de decidir sobre o próprio corpo permite a participação direta do cidadão nos assuntos que lhe digam respeito, empoderando-o e o fazendo efetivamente pertencente ao grupo social no qual está inserido.

A garantia de liberdades individuais relacionadas à reprodução e à sexualidade é parte da expressão política de um povo que pretende tomar para si o poder de decisão sobre seu próprio corpo, local em que há possibilidade de emancipação e de reafirmação de direitos.

Nada mais pessoal que o corpo e tampouco nada mais político. O corpo político situa-se não só atado ao privado ou ao ser individual, mas também vinculado integralmente ao lugar, ao local, ao social, ao espaço público. Sobre o corpo atuam o Estado, a comunidade, a família, a religião, o mercado, as forças fundamentalistas. "É através de uma grande quantidade de controles patriarcais que estas forças e instituições transformam os corpos das mulheres em expressões de relações de poder. Dessa maneira, os corpos das mulheres e as diversidades sexuais estão no centro de projetos autoritários ou democráticos" (Wendy Harcourt e Arturo Escobar). E muitas vezes a linha divisória entre "democrático" e "autoritário" se desvanece quando se trata do corpo. (EDITORIAL, 2007)

Ao se conceder o exercício da cidadania reprodutiva aos indivíduos, está-se assegurando que todos possam ocupar espaços públicos e privados com dignidade, o que favorece a subjetividade e a igualdade.

Ocorre que as práticas médicas capazes de criarem a vida em laboratórios, especialmente a gestação por substituição - que ocorre quando uma mulher gera em seu ventre o bebê que será entregue a terceiros quando do nascimento -, faz com que a sociedade se questione sobre o efetivo atingimento da cidadania reprodutiva.

Com efeito, ainda que se considere que os avanços biotecnológicos possibilitaram maior autonomia aos indivíduos, que agora podem livremente escolher quando, como e por 
quais maneiras pretendem ter filhos ${ }^{2}$, não se pode negar que há dúvidas quanto à eticidade do procedimento, tendo em vista que as mulheres gestantes - vulnerabilizadas pela pobreza e pela baixa escolaridade - nem sempre terão proteção jurídica, quando expostas ao mercado procriacional $^{3}$.

A situação de desamparo dos direitos da gestante é tão alarmante, que há registros no mundo todo sobre a possibilidade de clínicas ou pessoas solicitantes da gestação controlarem a vida dessa mulher durante o procedimento médico, fazendo-o por meio de contratos previamente assinados por todos os interessados. Neste contexto, o Dr. Nitesh, um dos profissionais envolvidos na contratação de uma gestação por substituição na Índia, pontua que:

Cuidamos bem delas [gestantes substitutas] no albergue substituto. Monitoramos sua nutrição, repouso e medicamentos para obter um melhor resultado. Elas estão sob nosso controle. A gravidez é delicada e muito preciosa. Acho que se alguém está fazendo algo por você, você deve cuidar disso. Nos países ocidentais, a gestante substituta pode não ser confiável, nem ter uma boa história ou experiência. Ela pode fumar, beber, fazer sexo e usar drogas. Ela não pode ser controlada. Ela pode até querer ficar com o bebê ou, mesmo que não haja apego emocional, parece querer mantê-lo para extorquir dinheiro. Em contraste, nossas substitutas são muito simples e religiosas. Não é um procedimento doloroso. ${ }^{4}$

\footnotetext{
${ }^{2}$ Em pesquisa qualitativa elaborada a partir da análise de entrevistas estabelecidas com 37 gays de países da Europa e dos EUA, que se valeram da gestação por substituição para se tornarem pais, o inglês Marcin Smietana, pesquisador associado à Universidade de Cambridge, demonstrou que a compreensão dos homens sobre suas próprias aspirações e oportunidades reprodutivas foram redefinidas com a possibilidade de uso da referida técnica médica. Com efeito, a autoconsciência dos homens como sujeitos que podem se reproduzir foi capaz de romper com a ideia heteronormativa de que sua orientação sexual os excluísse de contribuir para a perpetuação da espécie, da família e da nação, o que ampliou seus direitos enquanto cidadãos. (SMIETANA, 2018.)

${ }^{3}$ Segundo o relatório "A PRELIMINARY REPORT ON THE ISSUES ARISING FROM INTERNATIONAL SURROGACY ARRANGEMENTS”, elaborado pelo Permanet Bureau da HCCH, em várias ocasiões foi constatada a prática de tráfico internacional de pessoas para gestarem por outrem, como por exemplo, as mulheres polonesas supostamente recrutadas para viajarem para a Holanda, Bélgica e Alemanha (<www.independent.co.uk/news/world/poles-hired-as-surrogate-mums-in- - comércio ilegal - 1584960.html>, última consulta em 16 de março de 2012); as mulheres de Mianmar vendidas para homens chineses para trabalharem como gestantes substitutas, como parte de um esquema de tráfico (<www.chinapost.com.tw/china/local-news/other/2009/03/26/201716/China-returns.htm>, última consulta em 16 de março de 2012 ); preocupações relativas a práticas na Guatemala (ver, por exemplo, Articulação do Movimento do Parlamento Europeu para uma resolução sobre a Guatemala (06 de julho de 2005), que afirmou que "os abusos que ocorrem na Guatemala incluem gravidezes forçadas ou substitutas [...]") (Fonte: "Memorando: existe uma necessidade de regular os contratos internacionais de barrigas de aluguel em direito internacional privado?", escrito sob a instrução de Peretz Segal, do Ministério da Justiça de Israel, por Jennifer Chernick, BA Stanford University, 2009.) - Disponível em <https://assets.hcch.net/docs/d4ff8ecd-f747-46da86c3-61074e9b17fe.pdf>. Acesso em 10 Fev. 2020

${ }^{4} \mathrm{O}$ texto original está em inglês e diz: "We take care of them [surrogates] well in the surrogate hostel. We monitor their nutrition, rest, and medicines in order to get a better result. They are under our control. The pregnancy is delicate and very precious. I think if someone is doing something for you, you should take care of it. In Western countries, the surrogate may not be reliable, nor with a good history or background. She may smoke, drink, and have sex and drugs. She cannot be controlled. She may even want to keep the baby, or even if there is no emotional attachment, appear to want to keep it in order to extort money. In contrast, our surrogates are very simple and religious. It is not a painful procedure.” (MADGE V, 2014)
} 
Ao se contratar uma gestação por substituição, as clínicas aplicam comandos contratuais sem nem ao menos refletirem sobre a nocividade dessas disposições, tal qual Eichmann fazia ao cumprir normas que determinavam o extermínio dos judeus.

Assim, direitos tão caros à racionalidade humana, tais como a privacidade, a vida, a integridade física, moral e sexual das mulheres foram totalmente vilipendiados para que uma gestação por substituição parecesse mais "segura" para os pretensos pais.

Tal qual ocorreu nos campos de concentração, as clínicas médicas que realizam a gestação por substituição são um novo $c a m p o^{5}$, onde se permite a criação de um sistema paralelo, caracterizado por se tornar um estado de exceção ${ }^{6}$, em que a crueldade e vulgarização da vida humana são priorizadas e grandes maldades são produzidas.

Ao negar cidadania reprodutiva à mulher gestante, que não tem qualquer poder de decisão sobre o próprio corpo, as clínicas médicas em geral se amparam na suposta legalidade e licitude do ato médico, ao passo que a autonomia de vontades dos contratantes conduziu e autorizou a prática médica.

Sob o pretexto de auxiliar os desafortunados pela infertilidade física ou estrutural a atingirem o sonho de se tornarem pais, os médicos simplesmente obedecem ao Código de Ética da categoria e às disposições contratuais sem ao menos se questionarem sobre a real eticidade do ato.

Assim como Eichmann, os médicos procuram ascensão e destaque profissionais quando empreendem a criação da vida humana em detrimento da cidadania reprodutiva dos envolvidos na técnica médica, a desprezarem por completo a relevância social da função que desempenham e a não refletirem sobre as consequências da mera aplicação das normas e

\footnotetext{
${ }^{5}$ O termos "campo" foi cunhado pelo sociólogo Bourdieu (1998, p. 28) para designar “(...) as relações de força entre as posições sociais que garantem aos seus ocupantes um quantum suficiente de força social - ou de capital - de modo a que estes tenham a possibilidade de entrar nas lutas pelo monopólio do poder, entre as quais possuem uma dimensão capital as que têm por finalidade a definição da forma legítima do poder (de preferência a classe dominante, conceito realista que designa uma população real de detentores dessa realidade tangível que se chama poder." (BOURDIEU,1998.)

6 "É preciso refletir sobre o estatuto paradoxal do campo enquanto espaço de exceção: ele é um pedaço de território que é colocado fora do ordenamento jurídico normal, mas não é, por causa disso, simplesmente um espaço externo. Aquilo que nele é excluído é [...] incluído através da sua própria exclusão. [...] Na medida em que o estado de exceção é, de fato, 'desejado', ele inaugura um novo paradigma jurídico-político, no qual a norma torna-se indiscernível da exceção. [...] O campo é um híbrido de direito e de fato, no qual os dois termos tornaram-se indiscerníveis. [...] Ao invés de deduzir a definição de campo a partir dos eventos que aí se desenrolaram, nos perguntaremos antes: o que é um campo, qual a sua estrutura jurídico-política, por que semelhantes eventos aí puderam ter lugar? Isto nos levará a olhar o campo não como um fato histórico e uma anomalia pertencente ao passado (mesmo que, eventualmente, ainda verificável), mas, de algum modo, como a matriz aculta, o nómos do espaço político em que ainda vivemos." (AGAMBEN, 2010) 
cláusulas contratuais, atitude esta que, por si só, é capaz de gerar grandes sofrimentos e de banalizar o mal, na conceituação mais ampla pretendida por Hannah Arendt.

Atingir a cidadania reprodutiva através da reprodução humana medicamente assistida só é possível quando os profissionais da saúde refletem sobre os procedimentos médicos e sobre aquilo que estão de fato ofertando à sociedade. As práticas médicas que simplesmente obedecem a normas e disposições contratuais quase nunca atendem aos anseios dos cidadãos e por esta razão negam cidadania reprodutiva e direitos aos envolvidos.

\section{Conclusão}

A proposta deste artigo foi realizar uma efetiva comparação entre a irreflexão e a consequente banalidade do mal, expostos pela filósofa Hannah Arendt, com a prática médica que realiza a reprodução humana artificial, especialmente a gestação por substituição, a fim de demonstrar que tais atos, desprovidos de reflexão sobre a eticidade da contratação e da verificação de atendimento da cidadania reprodutiva de todos os envolvidos no procedimento, estão fadados a obstaculizar a direitos sexuais e reprodutivos, pois não garantem a autonomia e igualdade.

No decorrer do levantamento bibliográfico pode-se perceber que o exercício da cidadania reprodutiva não é apenas um conjunto de direitos dispostos em um ordenamento jurídico, mas é, sobretudo, o respeito à privacidade, à vida e à sexualidade de cada indivíduo envolvido na reprodução artificial.

Assim, no pensamento elaborado por Hannah Arendt, aplicar friamente as disposições contratuais pré-determinadas em um instrumento de adesão, fazendo-o de forma irreflexível, é capaz de produzir uma maldade sem precedentes, pelo que é preciso estimular o pensamento crítico do ser humano - independentemente do seu grau de intelectualidade e do cargo que ele ocupe -, a fim de evitar que barbáries como as que foram cometidas durante o Nazismo voltem a ocorrer.

\section{Referências}

AGAMBEN, Giorgio. Homo Sacer: o poder soberano e vida nua I. Tradução Henrique Burigo, 2. ed. Belo Horizonte: Editora UFMG, 2010, p. 164-166.

ANDRADE, Marcelo. A banalidade do mal e as possibilidades da educação moral: contribuições arendtianas. Rev. Bras. Educ., Rio de Janeiro, v. 15, n. 43, p. 109-125, Apr. 
2010. Disponível em: $<$ http://www.scielo.br/scielo.php?script=sci_arttext\&pid=S1413$24782010000100008 \& \operatorname{lng}=$ en $\& n r m=$ iso $>$. Acesso em: 11 Set. 2020

ARENDT, Hannah. Homens em tempos sombrios. São Paulo: Companhia de Bolso; 2008.

ARENDT, Hannah. Compreender: formação, exílio e totalitarismo. Belo Horizonte (BH): Companhia das Letras/Editora UFMG; 2008.

ARENDT, Hannah. A vida do espírito. Rio de Janeiro (RJ): Civilização Brasileira: 2009.

ARENDT, Hannah. Origens do totalitarismo. São Paulo: Companhia das Letras; 1998.

ARENDT, Hannah. Sobre a violência. Rio de Janeiro: Civilização Brasileira; 2009.

ARENDT, Hannah. A condição humana. Rio de Janeiro: Editora Forense; 2007.

ARENDT, Hannah. Eichmann em Jerusalém. Um relato sobre a banalidade do mal. Tradução de José Rubens Siqueira. São Paulo: Companhia das Letras, 1999A.

ÁVILA, Maria Betânia de Melo. Modernidade e cidadania reprodutiva. In: ÁVILA, Maria Betânia de Melo; BERQUÓ, Elza. Direitos reprodutivos: uma questão de cidadania. Brasília: Centro Feminista de Estudos e Assessoria - CFEMEA, 1994.

AVILA, Maria Betânia de Melo. Direitos sexuais e reprodutivos: desafios para as políticas de saúde. Cad. Saúde Pública, Rio de Janeiro, v. 19, supl. 2, p. S465-S469, 2003. Disponível em: $<$ http://www.scielo.br/scielo.php?script=sci_arttext\&pid=S0102-

311X2003000800027\&lng=en\&nrm=iso $>$. Acesso em 17 de Junho de 2020.

BIGNOTTO, Newton. \& MORAES, Eduardo Jardim. Hannah Arendt - diálogos, reflexões e memórias. Belo Horizonte: UFMG, 2003, p.138.

BOURDIEU, Pierre. O poder simbólico. 2. ed. Rio de Janeiro: Bertrand Brasil, 1998.

CHAVES, Rosângela. A capacidade de julgar. Um diálogo com Hannah Arendt. Goiânia. Canone Editorial, 2009.

EDITORIAL, Coordenação. Manifesto por uma convenção interamericana dos direitos sexuais e dos direitos reprodutivos. Revista Estudos Feministas, Florianópolis, v. 15, n. 1, jan. 2007. ISSN 1806-9584. Disponível em:

$<$ https://periodicos.ufsc.br/index.php/ref/article/view/7749>. Acesso em: 26 ago. 2020.

HAGUE CONFERENCE ON PRIVATE INTERNATIONAL LAW. A Preliminary Report On The Issues Arising From International Surrogacy Arrangements. 2012. Disponível em $<$ https://assets.hcch.net/docs/d4ff8ecd-f747-46da-86c3-61074e9b17fe.pdf $>$. Acesso em: 10 Fev. 2020

MADGE V (2014) Gestational surrogacy in India: the problem of technology and poverty. In: DasGupta S and Dasgupta SD (eds) (2014) Globalization and Transnational Surrogacy in India: Outsourcing life. Lanham, MD: Lexington Books, pp. 45-66. 
MATOS, OC. O Storyteller e o Flâneur: Hannah Arendt e Walter Benjamim. In: Moraes EJ, Bignotto N. Belo Horizonte (BH): Companhia das Letras/Editora UFMG; 2003.

SMIETANA, Marcin. Procreative consciousness in a global market: gay men'spaths to surrogacy in the USA. Symposium -Making Families. Reproductive Biomedicine and Society Online, Vol. 7, Nov. 2018. Disponível em:

$<$ https://www.ncbi.nlm.nih.gov/pmc/articles/PMC6465560/>. Acesso em: 27 Ago. 2020

SOUKI, N. Hannah Arendt e a banalidade do mal. Belo Horizonte (BH): Editora UFMG; 1998. 